Discussion Paper No. 13-035

Do Pay-as-bid Auctions Favor Collusion? Evidence from Germany's Market for Reserve Power

Sven Heim and Georg Götz

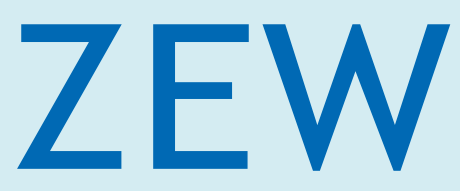

Zentrum für Europäische Wirtschaftsforschung $\mathrm{GmbH}$ Centre for European Economic Research 
Discussion Paper No. 13-035

\title{
Do Pay-as-bid Auctions Favor Collusion? Evidence from Germany's Market for Reserve Power
}

\author{
Sven Heim and Georg Götz
}

Download this ZEW Discussion Paper from our ftp server:

http://ftp.zew.de/pub/zew-docs/dp/dp13035.pdf

Die Discussion Papers dienen einer möglichst schnellen Verbreitung von neueren Forschungsarbeiten des ZEW. Die Beiträge liegen in alleiniger Verantwortung der Autoren und stellen nicht notwendigerweise die Meinung des ZEW dar.

Discussion Papers are intended to make results of ZEW research promptly available to other economists in order to encourage discussion and suggestions for revisions. The authors are solely responsible for the contents which do not necessarily represent the opinion of the ZEW. 


\section{Executive Summary}

Using bidding data on a firm-level basis which we received from the German Federal Network Agency (Bundesnetzagentur) we analyze a drastic price increase in the market for negative secondary reserve power in Germany between 2009 and 2010. As there were no conspicuous movements on the spot market of the European Energy Exchange (EEX) which serves as a substitute market for the owners of generation capacity eligible for producing reserve power, the price increase did not appear to be driven by increased costs. Against the background of several market-design modifications aiming to increase competition and liquidity in Germany's market for reserve power during recent years and an increasing number of market participants the price increase was even more surprising.

We study market structures and market power in the first stage and apply common measures like HHI, Concentration Ratios as well as measures developed for electricity markets like Pivotal Supplier Index (RSI) and Residual Supply Index (RSI). We identified a concentrated market with highly pivotal suppliers in an environment with completely price-inelastic demand and high entry barriers. Subsequently we analyzed individual bid strategies with regard to the present pay-as-bid auction design and its "guess the clearing price" principle. Our results suggest that the price increase can be traced back to a reduction in supply of the most dominant supplier and the interaction of the two most dominant suppliers' bidding strategies afterwards. Thereby a spiraling price increase was initiated by repeated pretended "bad guessing" and prices maintained on a higher level even after supply was brought back to its initial volume again.

We demonstrate the absurdity of the "guess the clearing price" idea behind discriminatory auctions in an environment with highly pivotal suppliers, inelasticity of demand, repeated auctions and the absence of demand uncertainty. While the first three characteristics can be found in virtually all energy markets, validity of our findings for energy markets in general depends on the degree of demand uncertainty and the frequency of similar market situations. Thus, given regulatory threats, the deemed main advantage of pay-as-bid auctions over uniform price auctions and the popular belief that they reduce dominant suppliers' withholding incentives and diminish their ability to tacitly collude can be rebutted as general rule. In fact, while strategic capacity withholding immediately leads to higher average prices for all suppliers in uniform price auctions, in pay-as-bid auctions bidders do not directly benefit from it but can generate extra-profits lagged by one period. We conclude that proving abusive behavior becomes harder in discriminatory auctions even when cost estimation is feasible since suppliers can hide behind the "guess the clearing price" principle and guessing prices wrong is not sufficient for legal prosecution. 


\section{Das Wichtigste in Kürze}

Trotz diverser Modifikationen des Marktdesigns, die darauf abzielten den Wettbewerb im Markt für Regelenergie zu stärken und die Liquidität des Marktes zu erhöhen, kam es zu einem drastischen Preisanstieg und einem Rückgang der Angebotskapazität im Markt für negative Skundärregelleistung zwischen 2009 und 2010. Da während der Beobachtungsperiode keine auffälligen Entwicklungen am Spotmarkt der European Energy Exchange (EEX), der für die Regelenergieanbieter ein Substitutionsmarkt darstellt und folglich die Opportunitätskosten determiniert, beobachtet werden konnten, kann die Preiserhöhung nicht durch einen Kostenanstieg begründet werden. Vor dem Hintergrund diverser Markteintritte im relevanten Zeitraum erscheint der Preisanstieg noch verwunderlicher.

Zur Analyse des Preisanstiegs wurden uns von der Bundesnetzagentur anbieterscharfe Gebotsdaten zur Verfügung gestellt. In einem ersten Schritt werden Marktstrukturen und Marktmachtsituation mit gängigen Indizes wie HHI und Konzentrationsraten sowie energiespezifische Indizes der Pivotal Supplier Index (PSI) und der Residual Supply Index (RSI) untersucht. Dabei wird ein stark konzentrierter Markt mit hochgradig pivotalen Anbietern in einer Umgebung mit unelastischer Nachfrage und hohen Eintrittsbarrieren identifiziert. Im nächsten Schritt werden individuelle Bietstrategien unter Berücksichtigung des vorliegenden pay-as-bid Auktionsprinzips mit seinem „Rate den Grenzpreis“ Prinzip analysiert. Unsere Ergebnisse weisen darauf hin, dass der Preisanstieg auf eine zwischenzeitliche Reduktion der Angebotskapazität des marktmächtigsten Anbieters und anschließender Interaktion der beiden marktmächtigsten Anbieter zurückgeführt werden kann. Durch die Angebotsverknappung und wiederholt vorgetäuschtem „schlechtem Raten“ kam es so zunächst zu einem spiralförmigen Preisanstieg; die Preise verblieben jedoch auch auf einem höheren Niveau nachdem die Angebotskapazität wieder auf ihr ursprüngliches Niveau zurückgeführt wurde.

Unsere Ergebnisse deuten darauf hin, dass dem pay-as-bid Mechanismus eine wesentliche Rolle bei der Erklärung des Preisanstiegs zukommt. Die verbreitete Meinung, dass pay-as-bid Auktionen gegenüber uniform price Auktionen den wesentlichen Vorteil besitzen, Anreize zu strategischer Kapazitätszurückhaltung zu eliminieren und Kollusion zu erschweren, kann dabei als generelle Regel widerlegt werden, sobald eine Regulierungsbehörde den Markt überwacht und Auktionen wiederholt stattfinden. Zwar führt strategische Kapazitätszurückhaltung in Knappheitssituationen bei uniform price Auktionen unmittelbar zu höheren Preisen für alle Anbieter, jedoch können die Anbieter mit ein-periodischer Verzögerung auch in pay-as-bid Auktionen dadurch höhere Erlöse realisieren. Eine Kostenbindung der Preise ist in pay-as-bid Auktionen aufgrund des „Rate den Grenzpreis“ Prinzip zudem nicht möglich. Die Macht der Regulierungsbehörde und somit das Abschreckungsinstrument wird dadurch deutlich eingeschränkt. Der Nachweis von missbräuchlichem Verhalten ist in pay-as-bid Auktionen folglich schwerer, da die Anbieter sich hinter dem „Rate den Grenzpreis“ Prinzip verstecken können und schlechtes Raten von Preisen kein hinreichender Grund für strafrechtliche Verfolgung darstellt. 


\title{
Do pay-as-bid auctions favor collusion? - Evidence from
}

\section{Germany's market for reserve power*}

\author{
Sven Heim †, Georg Götz
}

June 7, 2013

\begin{abstract}
We analyze a drastic price increase in the German auction market for reserve power, which did not appear to be driven by increased costs. Studying the market structure and individual bidding strategies, we find evidence for collusive behavior in an environment with repeated auctions, pivotal suppliers and inelastic demand. The price increase can be traced back to an abuse of the auction's pay-as-bid mechanism by the two largest firms. In contrast to theoretical findings, we show that pay-as-bid auctions do not necessarily reduce incentives for strategic capacity withholding and collusive behavior, but can even increase them.
\end{abstract}

Keywords: Auctions, Collusion, Market Power, Energy Markets, Reserve Power, Balancing Power JEL-codes: D43, D44, D47, L11, L13

${ }^{*}$ We are indebted to Justus Haucap, Kai Hueschelrath, Sebastian Just, Vigen Nikogosian, Matthias Otte (German Federal Network Agency), Jochen Patt (German Federal Network Agency), Dominik Schober, Florian Smuda and Michael Waterson for valuable comments on previous versions of the paper.

${ }^{\dagger}$ ZEW Centre for European Economic Research, Competition and Regulation Research Group; MaCCI Mannheim Centre for Competition and Innovation; University of Gießen; Address: L7,1, 68161 Mannheim, Germany; Email: heim@zew.de.

${ }^{\ddagger}$ University of Gießen, Email: Georg.Goetz@wirtschaft.uni-giessen.de 


\section{Introduction}

As many energy markets suffer from vulnerability to the abuse of market power, market design in general and auction design in particular is crucial to achieve efficient outcomes. Especially when bearing in mind that already little market design flaws result in tens of millions of extra costs, the evaluation of gaming incentives under different auction designs appears extremely important. During recent years academics as well as policy makers have debated on the superiority of either the uniform-price (UPA) or the discriminatory auction (also called the pay-as-bid auction, hereinafter PABA and PAB, respectively), trying to answer the question which mechanism is more appropriate to diminish susceptibility of electricity markets to market manipulation. Even though the UPA has several crucial advantages over the PABA (e.g. Cramton and Stoft, 2007), it is widely agreed that the PABA is less subject to collusion and strategic supply reduction. Our analysis, however, suggests the contrary.

Using bidding data on a firm-level basis which we received from the German Federal Network Agency (Bundesnetzagentur) we analyze a drastic price increase in the market for secondary reserve power in Germany between 2009 and 2010. ${ }^{1}$ As there were no conspicuous movements on the spot market which serves as a substitute market for the owners of generation capacity eligible for producing reserve power, the price increase did not appear to be driven by increased costs. Against the background of several market-design modifications aiming to increase competition and liquidity in Germany's market for reserve power during recent years and an increasing number of market participants the price increase was even more surprising.

In particular, we focus on market power issues and individual bidding behavior with regard to the present discriminatory auction design. Our results suggest that the price increase was triggered by strategic interaction of the two most powerful firms which can be traced back to an abuse of the "guess the clearing price" principle of discriminatory auctions through repeated pretended bad guessing. We show that auction design is a crucial instrument for the regulatory authority's monitoring power and the mitigation of problems arising from market power and collusion. Furthermore, we demonstrate the absurdity of the "guess the clearing price" idea behind discriminatory auctions in an environment with highly pivotal suppliers, inelasticity of demand, repeated auctions and the absence of demand uncertainty. While the first three characteristics can be found in virtually all energy markets, validity of our findings for energy markets in general depends on the degree of demand uncertainty and the frequency of similar market situations.

To the best of our knowledge this is the first paper providing empirical evidence on collusive behavior in a PABA organized electricity market and thus rebuts the popular belief that this pricing

\footnotetext{
${ }^{1}$ In Germany as in the whole ENTSO-E (European Network of Transmission System Operators for Electricity) area there are three different qualities (and thus markets) of reserve power: Primary Reserve, Secondary Reserve and Tertiary Reserve (also called minute reserve).
} 
system is less subject to collusion and strategic capacity withholding problems; to the contrary: it can even increase them. As there is a vast array of literature in auctions it is somehow surprising that one additional important difference between uniform and discriminatory pricing has been largely neglected: the regulatory authority's ability for legal prosecution. To our knowledge only Kahn et al. (2001) shortly mention the greater transparency of bidding behavior under a UPA in detecting collusive or quasi-collusive pricing as "another possibly important difference". In the course of this paper we will show that this difference is crucial for detecting and mitigating incentives to exercise market power since PABA reduce monitoring power and intervention legitimation of regulatory authorities.

The remainder of this paper is structured as follows: Subsequent to a review of the related literature in section 2, an overview of functioning and design of the reserve power market and our motivation is carried out in section 3. Thereafter we conduct empirical analyses consisting of a market power analysis section (5.1) and a price and bidding strategy analysis section (5.2). Section 6 concludes the paper with a summary and policy implications.

\section{Literature Review}

Literature dealing with the efficiency of reserve power markets is rather scarce. Most articles examine pricing on the minute reserve market and consider the level of integration with the spot market as measure of efficiency (Growitsch et. al (2007), Mueller and Rammerstorfer (2008), Growitsch and Weber (2008)). Swider and Weber (2007) model optimal bidding under priceuncertainity in reserve power markets with discriminatory auctions. Potential collusive behavior and pivotal power are not part of their study and each supplier only offers a single bid with a price-dependent probability of acceptance instead of a discrete supply curve. Growitsch et al. (2010) analyze market power in the minute reserve market and find a tight oligopoly and a high concentration. As the market for minute reserve power is the most competitive reserve power market by far due to less restrictive participation requirements and the resulting higher number of suppliers, it is likely that the market for secondary reserve power is even more susceptible to market power problems. For the more specific case of secondary reserve power Just and Weber (2008) model the interdependencies between the secondary reserve market and the spot market to derive the pricing of reserves under equilibrium conditions. They provide a numerical solution procedure to this case of market interaction. Related to their paper Richter (2011) investigates the problem analytically and proves that a unique efficient competitive equilibrium exists. Both articles assume competitive markets, thereby abstracting from the potential existence of market power and non-competitive bidding, but as mentioned above it seems doubtful that markets are 
competitive. Furthermore, auctions are modeled as UPA although they actually are PABA. This should not influence prices significantly in a competitive environment so that their results can be considered as a benchmark for competitive prices. However, as we will show later auction design becomes an important factor when market power is taken into account and has a substantial impact on bidding strategies.

During recent years scientists as well as policy makers have debated on the superiority of either UPA or PABA, trying to answer the question which mechanism is more appropriate to to achieve efficient market outcomes. The two types differ in the way payments for awarded bids are determined. In UPA all successful bids receive the same price which typically corresponds to the last accepted bid, the marginal price (first-price auction). This price is paid to winning suppliers regardless of their actual bids. By contrast such a single price does not exist in a PABA where each successful bid is exactly paid its submitted price. While all electricity markets have been organized as UPA until the beginning of the millennium, this changed with the 2001 England and Wales electricity market reform (New Electricity Trading Arrangements, NETA) ${ }^{2}$ and the associated adoption of a PAB settlement. The British energy regulator Ofgem (Office of Gas and Electricity Markets) initiated this switch due to a weak market performance and manipulation in the past, in the belief that incentives to exercise market power would thereby be reduced considerably. However, the switch was just one of many simultaneous changes in the market which hampers attempts to isolate single effects. ${ }^{3}$ Shortly afterwards in 2001, the California Power Exchange considered a switch from uniform to discriminatory pricing for the same reasons. The proposal was rejected after a commission of leading auction economists had argued against PABA (Kahn et al., 2001). Even though the UPA clearly has several crucial advantages over the PABA (e.g. Cramton and Stoft, 2007), it is widely agreed that this settlement approach provides clear incentives for large companies to tacitly collude and exercise market power by withholding some share of their capacity when demand is high and close to the available capacity. This is due to the fact that with rising demand the merit order curve gets increasingly steep whereas demand for electricity is extremely price-inelastic in the short-run. Thereby a dominant supplier can increase the market clearing price and thus the pay-off for all accepted bids without raising his own marginal price. Hence, supply reduction can be a profitable strategy for large players in UPA in order to make expensive peak-units necessary to meet demand. By contrast, withholding capacity constitutes a risk in discriminatory auctions because a supplier must additionally raise prices for all of his bids and thereby has more to lose by underestimating the liquidity of the market.

\footnotetext{
${ }^{2}$ In 2005 the Scottish market joined the NETA which changed its name to BETTA (British Electricity Trading and Transmission Agreements) afterwards.

${ }^{3}$ Evans and Green (2004), Fabra and Toro (2003) or Bower (2002) and Newberry (2003) all differ in their conclusions.
} 
Several empirical studies provide evidence for abusive capacity withholding in UPA. Joskow and Kahn (2002) have proven abusive capacity withholding in California, Wolak and Patrick (2001) as well as Wolfram (1998) for the England and Wales market. Referring to the California electricity market Cabral (2002) suggests that a switch from UPA to PABA would reduce much of the market power created by strategic capacity withholding and marginal plant overbidding. The same line is taken by Hudson (2000), who argues that discriminatory auctions may potentially reduce instances of strategic capacity withholding. Holmberg (2009) states that withholding capacity can not be optimal in a PABA since suppliers have incentives to bid under the price cap and that the risk of collusion is lower in a PABA. In a theoretical model with repeated divisible goods auctions Fabra (2003) shows that the UPA facilitates collusion more than discriminatory auctions and is more vulnerable to the abuse of market power in electricity markets (Fabra, 2007); Klemperer (2002) argues along similar lines stating that in electricity markets collusion is harder in a PABA because bids cannot longer be used as costless threats. In their comparison of the two auction formats Federico and Rahman (2003) conclude that a switch from UPA to PAB would generally reduce market power. However, the authors state that on the other hand such a switch would diminish entry probability of small suppliers as they cannot free-ride anymore on high prices caused by large players' bidding behavior. Their results are derived by assuming demand uncertainty for the cases of perfect competition and monopoly, however, abstracting from interaction. In the context of oligopolist interaction they argue that "on the basis of existing results from multiunit auction theory, switching from UPA to PABA may have significant effects in this case, by changing the nature of competition from "Cournot" to "Bertrand" with an associated reduction in market power." With regard to the relationship between collusion and the auction price rule, they argue that due to aggressive infra-marginal bidding UPA facilitates collusive outcomes relative to PABA. Dechenaux and Kovenock (2007) analyze tacit collusion in repeated multi-unit auctions and assume a symmetric oligopoly with capacity-constraint firms. They find that collusion is easier in UPA than in PABA and capacitiy withholding may be necessary to sustain this result. In their fundamental paper Ausubel and Cramton (2002) claim that UPA can lead to inefficiencies since it provides incentives for supply reduction while by contrast this incentive does not exist in a discriminatory auction. However, they conjecture that this is not necessarily an argument against UPA since the exercise of market power favors smaller bidders in UPA. In the context of reserve power markets this view is shared by Mueller and Rammerstorfer (2008). The authors argue that on the one hand collusion is more probable and incentives for collusive behavior are higher under UPA as PAB pricing reduces strategic incentives due to the fact that the paid amount depends on the own bid instead of the highest marginal price. On the other hand they state PAB mitigates competition since smaller companies do not benefit from the abuse of market power by larger 
companies.

Nevertheless, our analysis leads to a contrary conclusion. Our findings support the results from the Rassenti et al. (2003) experimental study which concludes that "Under the conditions of cyclic and revealed inelastic demand, the DPA (Discriminatory Price Auction) invites sellers to tacitly collude, coordinating their offers without explicit communication at the highest previously observed price in a similar period. Having established that such coordination is not present in the UPA, our experiment demonstrates that it is the incentive structure of the DPA institution that promotes this tacit collusion."

\section{Functioning of the Reserve Power Market}

A main criterion when evaluating the quality of an electricity systems is its level of supply security. In this context a clear distinction is generally made between the long-term and the short-term dimension. Whereas in the long-term investment in grid and generation capacity is crucial for reaching an appropriate security of supply level, the focus of the present paper is on the shortterm, where a continuous and uninterruptable supply is required. However, ensuring this requires consideration of the special nature of electricity. First of all, electrical energy is a grid-bound and economically non-storable good. Furthermore, the maintenance of an equilibrium between electricity fed into and withdrawn from the grid is required at each point in time. If this condition is not met, grid frequency deviates from the setpoint value and hence may cause wide-spread blackouts. However, deterministic and stochastic imponderables (for instance unforeseen power plant outages, incorrect prediction of consumer load or forecast errors of intermittent renewable energy production) permanently lead to unavoidable imbalances between production and consumption of power. Due to the non-storability the balance of discrepancies between scheduled supply and load that occurs after the intraday market's gate closure (which serves as last option to adjust schedules via trading) is only feasible through real-time generation.

In Germany as in entire Europe the responsibility for a stable grid operation is centralized and lies with the transmission system operators (TSO). Accordingly, the continuous balancing of frequency deviations is one of their major tasks. TSO therefore have to stockpile flexible reserve generation capacities and activate them in the case of need. We will refer to these capacities hereinafter as reserve power. ${ }^{4}$

\footnotetext{
${ }^{4}$ There is a long list of synonymously used terms such as control power/energy, regulating power/energy, balancing power/energy or reserve capacity.
} 


\subsection{Market Design}

A distinction is made between two types of reserve power whose utilization depends on the system's net imbalance. If real-time generation exceeds scheduled demand then negative reserve is called. Units that are eligible for producing reserve power then reduce generation or demand-side activates extra-load. Similarly, in the case of electricity deficits in the grid, positive reserve is activated by increasing electricity production or cutting down consumer load. In Germany as in virtually all European markets, reserve power is classified in three different qualities (and subsequently three different auction markets) with regard to their activation and response time, namely primary reserve $(P R)$, secondary reserve $(S R)$ and tertiary reserve (also called minute reserve, hereinafter $M R) .{ }^{5}$ Their activation order follows the principle of hierarchical substitution: PR balances deviations within seconds. It restores frequency immediately and subsequently is substituted and complemented by SR after a maximum of 30 seconds. SR has to reach full response within 5 minutes. In the case of persisting system failures TSO activate MR within 15 minutes, thereby releasing PR and SR capacities and making them available again for further imbalances. TSO attract reserve power in a separate market which is organized as a web-based procurement auction. However, participating in the reserve power market requires generation plants to fulfill high technical standards which they have to prove in so-called prequalification procedures. Due to these requirements only few types of plants are licensed to provide their capacities as reserve power. Furthermore, it is costly and lasts up to one year for a company to go through the prequalification procedure until they finally can provide reserve power. This indicates that reserve power markets are not likely to be very competitive and thus susceptible to problems arising from market power. 6

It is important to note that the dimensioning of reserve capacities is computed on the basis of stochastic criteria (shortfall probability) and serves as an ancillary service. Due to this fact TSO are legally obliged to procure the calculated reserve in order to ensure a determined level of supply security, regardless of the price. Thus, TSO are confronted with a completely price inelastic demand. Moreover, because plant outages and incorrect load prediction were the main sources of net imbalances so far, the rising share of fluctuating renewable energy in total energy generation is expected to significantly increase forecast errors of electricity generation and hence TSO's demand for reserve power. In other words: an efficient reserve power market design becomes increasingly important.

In most European countries reserve power markets are organized as procurement auctions. They

\footnotetext{
${ }^{5}$ A good overview is provided by the 2012 ENTSO-E survey.

${ }^{6}$ According to the German Federal Network Agency's 2011 monitoring report there were 8 suppliers of PR, 11 for SR and 28 for MR in 2011. The German Monopolies Commission stated in their 2007 special report power and gas, that they do not expect effective competition in the markets for PR and SR in the foreseen future.
} 
mainly diverge in the auction's settlement method and are designed either as PABA or UPA. ${ }^{7}$ In Germany, their organization is even determined by law as discriminatory auctions. ${ }^{8}$ While MR auctions take place day-ahead right before the spot market auctions of Europe's leading energy exchange, the EEX (European Energy Exchange), those for SR and PR took place on a monthly basis during the observation period. ${ }^{9}$ Each bid consists of a bidden capacity and two price components (multi-part auction): the capacity price serves as a capacity option and pays the awarded bids for keeping the capacity available, thereby acknowledging the fact that the same capacity can not be sold twice and thus is dead for the spot market trade. By contrast, the second component, the energy price, is only paid when capacity is actually activated. In a well-functioning market capacity prices should reflect opportunity costs such as foregone spot market profits while energy prices should mirror actual costs of generation. Bids are selected solely on the basis of their capacity prices because the actual utilization of reserves is unknown ex ante due to the stochastic nature of imbalances. TSO award as many bids as required to cover demand (multi-unit auction). The awarded bids are then called upon in the order of their energy prices when imbalances occur. As every supplier can submit several bids by splitting up his available capacity, one speaks of divisible good auctions. Furthermore, no supplier has any information on the other suppliers' offers which makes it a sealed-bid auction. As the quantity of reserve capacity to be procured is published ex ante, there is no demand uncertainty.

\subsection{Recent Developments and Research Motivation}

Several market design and participation requirement adjustments have been implemented during recent years, aiming to reduce entry barriers and increase intensity of competition. The creation of a uniform market for secondary reserve, realized with the start of the German Grid Control Cooperation (GCC), can be considered as the most important change since the adoption of the common web-based procurement auction in December 2006 (tertiary reserve) and December 2007, respectively (primary and secondary reserve). ${ }^{10}$ Indeed, although secondary reserve has already been procured jointly in a common tender since 2007, the four TSO had to balance their control areas independently of one another which caused an uncoordinated balancing between them. As this permanently led to situations in which positive reserve power was needed in a certain control area while at the same time negative reserve was called in another one, there has been inefficient capacity utilization beforehand which resulted in an excessively high provision of reserve capacity.

\footnotetext{
${ }^{7}$ See Rivero et al. (2011) for a comparison of the different auction designs in several European countries.

${ }^{8}$ According to $\$ 8$ of the Electricity Network Access Ordinance (StromNZV).

${ }^{9}$ This changed in June 2011 with the adoption of a weekly auction for PR and SR. Beforehand, until December 2007, they took place biannually.

${ }^{10}$ Beforehand the four German TSO had to procure reserve capacity for their control areas individually. With the implementation of a web-based procurement auction in December 2007, the four formerly divided reserve capacity markets were transferred into a common unified market with joint tenders.
} 
These inefficiencies were eliminated in May 2009, when three of the four German TSO started the GCC; it was completed in May 2010 with the accession of the fourth TSO Amprion.

As these changes were expected to increase competitiveness and liquidity, the German Federal Network Agency was confronted with a sharp rise of prices for negative secondary reserve in the nighttime (Neg NT), which had almost tripled in the time span between January 2009 and December 2010 (Figure 1). At the same time prices of the other three secondary reserve products remained stable or even decreased. ${ }^{11}$ The drastic price increase was accompanied by a meanwhile decrease in liquidity and induced situations of scarcity, in which demand could not be covered even though it is price-inelastic (Figure 2). ${ }^{12}$

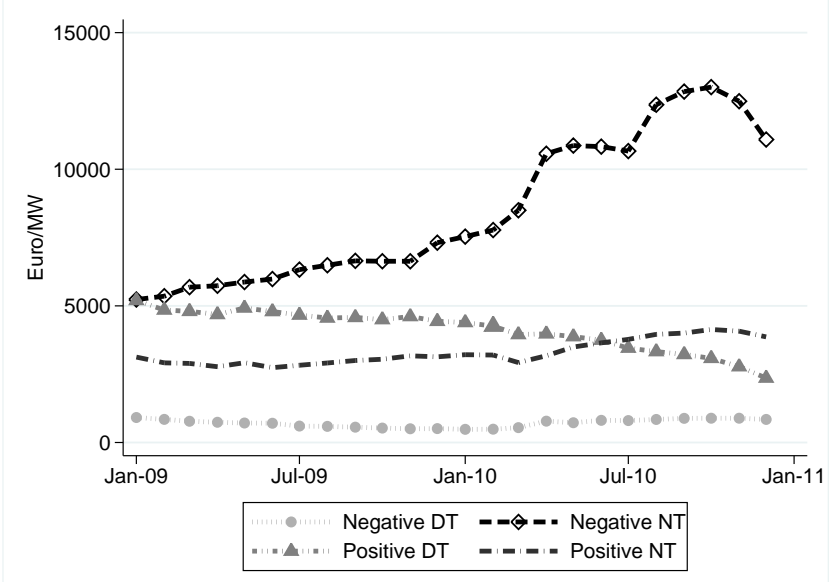

Figure 1: Price development for secondary reserve

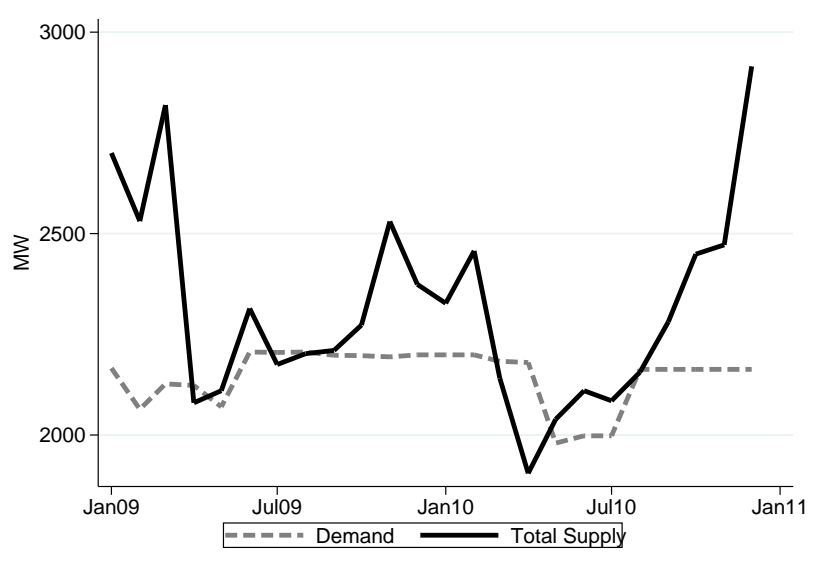

Figure 2: Development of liquidity in the market for negative secondary reserve during the nighttime (Neg_NT)

Against the background of no significant developments on the spot market, which provides a

\footnotetext{
${ }^{11}$ Seondary reserve is split into four products: a day-time and a night-time product for positive as well as negative secondary reserve.

${ }^{12}$ We define liquidity here as ratio of supplied capacity and demand.
} 
substitute market for the owners of prequalified units, and an increase in the number of market participants from 5 to 8 between 2009 and 2010, this development was even more surprising. Unfortunately, a robust (marginal or opportunity) cost estimate cannot be accomplished as there is no information on the types of the prequalified units publicly available. Furthermore, suppliers only bid capacities rather than specific plants and in the case of need then decide in a short-term portfolio optimization which of their plants can produce reserve power in the most cost-efficient way. ${ }^{13}$ As the price increase did not appear to be supported by increased costs, the Federal Network Agency provided us with anonymized bidding-data for the relevant years 2009 and 2010 in order to examine this development.

Using this unique dataset we investigate the following key research questions in the course of this paper:

- How does the market structure look like and what degree of market power exists?

- Are there conspicuities in the observed bidding behavior?

- Is there evidence for an abuse of market power?

We analyze market structures and market power in a first step and examine individual bids and strategies afterwards.

\section{Data and Descriptive Statistics}

The data provided by the German Federal Network Agency contain detailed bid information for the 24 monthly secondary reserve power auctions that took place in 2009 and 2010. In total we have firm-specific but anonymized information for 3958 bids including all four products for secondary reserve. Each bid consists of the anonymized firm name (e.g. supplier 1, supplier 2...), bidden capacity in MW, charged capacity price, charged energy price, corresponding month and status of acceptance (yes/no). For negative reserve power in the night-time (Neg_NT) we have individual data for 978 bids. Due to the observed price increase, our analysis focuses on this reserve product. The data enable a detailed analysis of market power and individual bidding strategies. Table 1 contains initial descriptive statistics. The number of participants in these auctions varies between 5 and 8 with 5 at the beginning and 8 at the end of the observed period. The bids had an average volume of 56.9 MW, however, varying in a wide range from $10 \mathrm{MW}$ to $500 \mathrm{MW}$. In some auctions every bid was accepted.

\footnotetext{
${ }^{13}$ The German Federal Cartel Office tried to collect data of the activated plants for the 2011 sector inquiry; however suppliers were unable to reliable reconstruct the activation procedure ex post, especially in the case of negative reserve.
} 


\begin{tabular}{l|llll}
\hline & mean & $\min$ & $\max$ & std. dev. \\
\hline \hline Bid size in MW & 56.9 & 10 & 500 & 61.2 \\
\hline Capacity charge in $€ / M W$ & 9811.4 & 3990 & 27996 & 3477.5 \\
\hline Number of suppliers & 6.5 & 5 & 8 & 1.1 \\
\hline Bids per month & 40.75 & 20 & 76 & 15.1 \\
\hline Share of accepted bids in \% & 92.2 & 61.8 & 100 & 0.092 \\
\hline
\end{tabular}

Table 1: Descriptive statistics for Neg_NT

\section{Empirical Analysis}

\subsection{Market Power}

Conceptually, market power represents the ability of one or more firms to influence prices in their favor and thereby realize higher profits. The traditional method for measuring market power in energy markets is via concentration indices. ${ }^{14}$ The most common indices of this kind are the Herfindahl-Hirschman-Index (HHI) which for instance is used by the US Department of Justice and the Federal Trade Commission in their Horizontal Merger Guidelines, and Concentration Ratios $(\mathrm{CRn})$ of the $\mathrm{n}$ suppliers with the highest market shares. The latter one for instance is used in the German Act against Restraints of Competition (GWB) to identify dominant market players. Although their explanatory power for energy markets is viewed critically, we start our analysis with HHI and CRn to give a first indication on market structures. ${ }^{15} \mathrm{HHI}$ is calculated by summing up the squared market shares of all suppliers multiplied by 10.000. Calculating the HHI on the basis of individual turnovers provides a value of 2674 and is thus above the critical values of 1800 and 2500, respectively, which define a highly concentrated market. ${ }^{16} \mathrm{CRn}$ measures the joint market shares of the $n$ largest players. Results also point towards a high market concentration given the critical values defined in the GWB are always exceeded (Table 2) .

\begin{tabular}{c|cccc}
\hline & CR1 & CR3 & CR4 & CR5 \\
\hline \hline Results Negative NT & 0.37 & 0.84 & 0.95 & 0.98 \\
\hline (Critical Values) & $(0.33)$ & $(0.50)$ & $(0.67)$ & $(0.67)$ \\
\hline
\end{tabular}

Table 2: Concentration ratios and critical values for the Neg_NT market

Considering that characteristics of energy markets are fundamentally different from conventional goods, concentration indices only have limited explanatory power. The main critique is their static perspective. Energy demand varies during the day, so that even if concentration is not very high on average, there are hours in which a substantial level of concentration exists. However, this argument does not hold for reserve power markets as demand is almost constant in the

\footnotetext{
${ }^{14}$ Schmalensee and Golub (1984).

${ }^{15}$ Despite substantial criticism most regulatory and competition authorities still (or again) use market-share based indices such as the CR or the HHI (E.g. FERC or the German Federal Cartel Office).

${ }^{16}$ While in the US Horizontal Merger Guidelines the critical HHI value was raised from 1800 to 2500 in 2010 , most economic articles still use 1800 .
} 
observed period, at least in the case of negative secondary reserve. ${ }^{17}$ Nevertheless, market-share based indices have a further crucial disadvantage because they only consider the supply side. This ignores that even for low HHI and CR values some suppliers can have significant market power if the quotient of demand and available capacity is small and price elasticity of demand is low. ${ }^{18}$ Figure 2 above shows that this is clearly the case in the observed market and that demand can not even be covered in some auctions. ${ }^{19}$

To address these properties, further measures are additionally used to quantify market power. The Pivotal Supply Index (PSI) is a binary index and measures the percentage share of auctions in which a certain supplier is essentially needed to cover demand, and thus is called pivotal. The results of the PSI are depicted in Figure 3. The PSI reveals Supplier 5 (S5) as most dominant supplier since he is pivotal in all auctions. Suppliers 2 (S2) and 10 (S10) are both pivotal in over 80 percent and Supplier 1 (S1) is pivotal in over 60 percent of all auctions. Although the aggregated fringe suppliers make up just 5 percent of the revenue based market share according to the Concentration Ratios displayed above, they are pivotal in about half of all auctions.

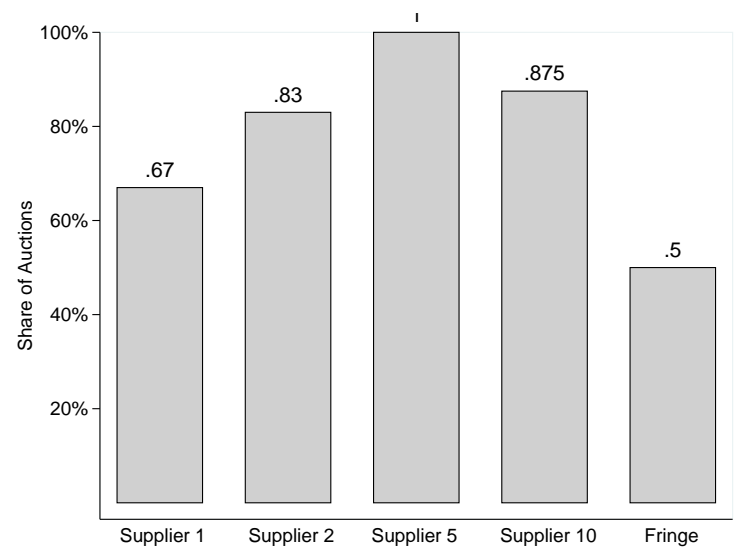

Figure 3: Pivotal Supplier Index results

A similar index is the Residual Supplier Index (RSI) which was developed by the Californian System Operator (CAISO). ${ }^{20}$ The RSI is a continuous variation of the binary PSI. It measures the percentages of the total demand which can be covered after deduction of a certain supplier j's capacity with

$$
R S I_{j}=\frac{\sum_{i \neq j}^{n} \text { Supply }_{i}}{\text { TotalDemand }}
$$

Whereas PSI only reveals whether a certain supplier is pivotal or not, the RSI displays the individual degree of pivotal power. ${ }^{21}$ The RSI outcomes are illustrated in Figure 4. Again, S5 appears as

\footnotetext{
${ }^{17}$ The demand for positive secondary reserve sank significantly after implementation of the GCC.

${ }^{18}$ See Borenstein et al. (1999) for a discussion on the weakness of concentration measures in the electricity sector.

${ }^{19}$ When TSO cannot cover demand a second auction is conducted. Nevertheless, they still were not able to attract sufficient reserve capacity in some cases.

${ }^{20}$ e.g. Sheffrin (2001), Sheffrin (2002a), Sheffrin (2002b).

${ }^{21}$ Twomey et al. (2004) provide a good overview on methods to measure market power in electricity markets.
} 
the most dominant player and is pivotal for almost up to the half of the price-inelastic demand in some auctions. Moreover, his RSI value is always above 75 percent which makes him pivotal for at least a quarter of demand. The RSI additionally reveals S2 as the second most dominant supplier. According to Sheffrin (2002), the RSI has a negative linear correlation with the Lerner-Index, where a RSI of 1.2 (120 percent) represents a Lerner-Index value of 0 and a RSI of 0.8 (80 percent) a Lerner-Index value of 1 . This emphasizes the high degree of market power in the observed market. Although the existence of market power must not necessarily cause its exercise, it clearly offers opportunities to behave strategically. We therefore analye individual bidding strategies in greater detail in the next section .



Figure 4: Illustration of Residual Supply Index values

\subsection{Price and Bidding Strategy Analysis}

Pay-as-bid inherently yields to individual prices for every bid. Whereas in a uniform-price setup price-taking suppliers have strong incentives to charge marginal or opportunity costs, they are forced to deviate from that tactic in discriminatory auctions. However, bidding above marginal costs has nothing to do with exercising market power in a PABA. To maximize their profits and cover their investment costs suppliers have to try to bid as close as possible below the expected marginal price even in a perfectly competitive environment. For this reason, it is often argued that bidding in discriminatory auctions corresponds to the "guess the marginal price"-principle.

A first indication of unilateral exercise of market power is provided by considering individual average prices per MW. Table 3 reveals that the most dominant suppliers S2 and S5 achieve 
significantly higher prices than both S1 and S10. ${ }^{22}$ Moreover, S5 and S2 supply the highest capacity on average, however, they differ considerably in their bidding strategies. Whereas S5 only supplies a small number of bids but with high capacity, S2 chooses the contrary strategy with a multitude of little volume bids. We will closer investigate this phenomenon later on.

\begin{tabular}{l|lllll}
\hline & S1 & S2 & S5 & S10 & Fringe \\
\hline \hline$\varnothing$ supplied capacity per auction (MW) & 247.9 & 570 & 840 & 516.8 & 58.9 \\
\hline$\varnothing$ bid size (MW) & 65.4 & 43.4 & 148.1 & 39.4 & 12.7 \\
\hline$\varnothing$ accepted capacity per auction (MW) & 245.5 & 493.9 & 753.1 & 503.2 & 50.49 \\
\hline$\varnothing$ quant. weighted capacity charge & 7083 & 8908 & 8559 & 7813 & 10515 \\
$(€ /$ MW) & & & & & \\
\hline$\varnothing$ number of bids per auction & 3.8 & 13.1 & 5.7 & 6.8 & 4.6 \\
\hline$\varnothing$ price var. of bids per auction & 136.9 & 1897.1 & 579.3 & 605.9 & 628.4 \\
\hline
\end{tabular}

Table 3: Supplier specific descriptive statistics for the Neg_NT auctions

In the next step we consider the development of the market's liquidity. It turns out that the significant reduction in liquidity and the related bottleneck was mainly triggered by the most dominant supplier S5, who had meanwhile reduced his supply by more than half of his initial volume from $1294 \mathrm{MW}$ to $595 \mathrm{MW}$ (Figure 9). This also explains the sharp horizontal shift of the RSI values of all suppliers except of S5 in the upper region of Figure 4.

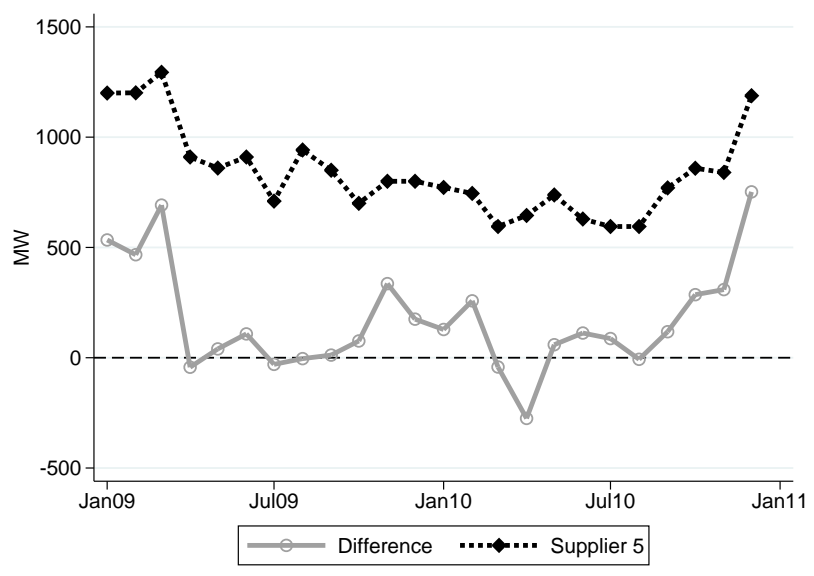

Figure 5: Development of Supplier 5's supply and difference between total supply and demand

S5's reduction in supply resulted in situations in which the TSO were not able to procure the tendered demand. In these auctions every bid was accepted due to completely inelastic demand. However, it is clear that a pivotal supplier does not have to reduce his supply in order to increase prices for his pivotal capacity. If he wants to achieve higher prices, he can just charge them and bids still get awarded. The crux is that a regulatory authority monitors the market and if a pivotal supplier unilaterally raises his prices, this would be suspicious and could possibly lead to the opening of abuse of market power procedures. In fact, charging prices above marginal costs is in

\footnotetext{
${ }^{22}$ The even higher average prices of the fringe suppliers are due to their later entries when prices were already on a higher level.
} 
principle forbidden to dominant suppliers on the EEX, which is organized as UPA. ${ }^{23}$ Charging prices above marginal costs is called financial or economic withholding when it results in a higher market clearing price. The alternative and more popular (because less detectable) abusive withholding strategy in UPA is physical or quantity withholding. ${ }^{24}$ The main advantage of abusive physical withholding is that suppliers do not have to increase their prices themselves but rather let the market carry out this task. Thus, those firms that charge high prices at the margin need not to be the ones exercising market power but may just have higher marginal costs. Nevertheless, their bids only get awarded due to the fact that beforehand a dominant firm has bidden less than its available capacity and thereby has shortened total supply abusively. Both types of withholding are subject to exploitative abuse. ${ }^{25}$

Thus, there are only two possible explanations: S5's capacity was not available due to technical restrictions or withheld abusively. According to the properties which are generally attributed to PABA (see Section 2), the latter reason does not seem very plausible and initially weakens the suspicion of abusive withholding. The limited possibility to exercise market power by withholding capacity is considered to be the main advantage of discriminatory auctions as stated above. Besides the claimed reduction of incentives for collusive behavior, it is the main reason why discriminatory auctions are implemented and even determined by law in several reserve power markets that are thought to be particularly vulnerable to market power problems (Vandezande, 2011). However, the German Federal Network Agency had no information on technical restrictions of prequalified plants in this magnitude for the relevant period.

In the next step we consider realized overall marginal prices and the highest accepted bids of the most dominant suppliers S5 and S2. They are illustrated in Figure 6. Two conspicuities can be pointed out: S2 determines the overall marginal price in most of the auctions, especially in the initial phase of the price increase. Furthermore, S5 seems to set his individual marginal prices according to the previous period's overall marginal price and thus follows the lagged individual marginal prices of S2. This procedure is highlighted in Figure 7 which depicts S2's and S5's individual marginal prices lagged by one period.

\footnotetext{
${ }^{23}$ According to the interpretation of the German Federal Cartel Office of GWB $\S 19,29$ and Art. 102 Treaty of the Functioning of the EU (TFEU) in the 2011 Sector Inquiry.

${ }^{24}$ While it is hard to identify whether a bidder shortens supply due to technical restraints or rather withholds quantity abusively, determining marginal costs is the easier task.

${ }^{25} \S 19$ GWB and Art. 102 TFEU.
} 


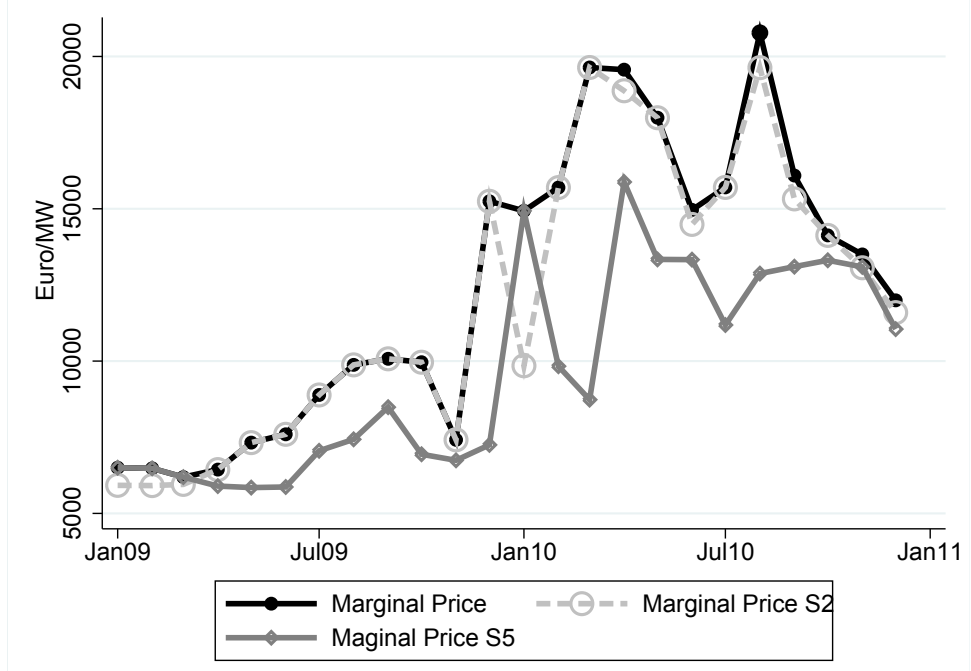

Figure 6: Development of overall marginal prices, marginal prices of Supplier 2 and marginal prices of Supplier 5

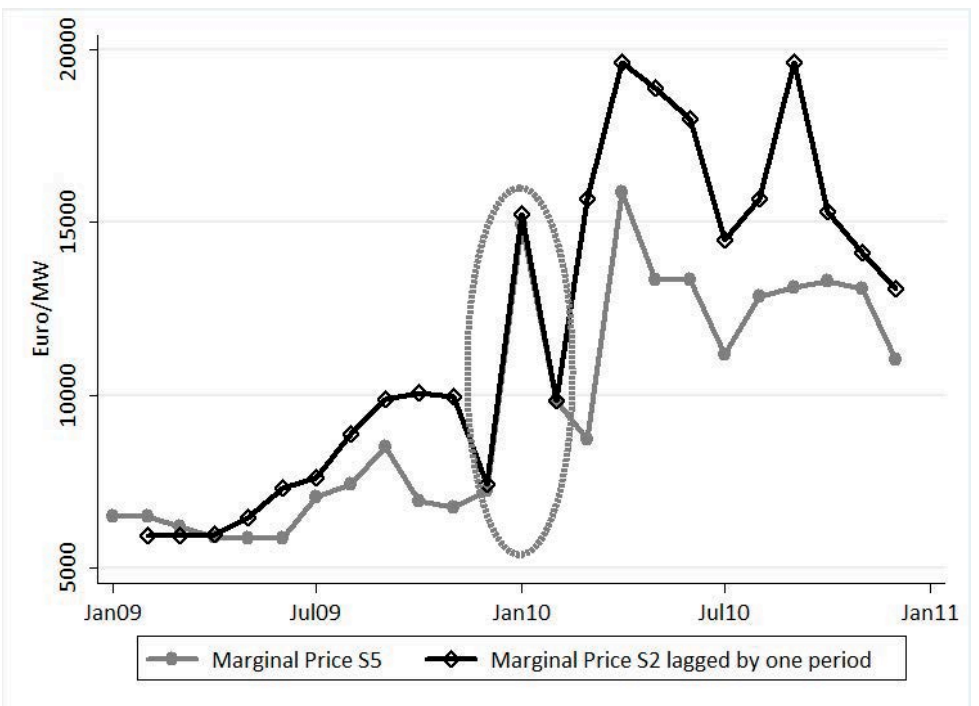

Figure 7: Marginal prices of Supplier 5 and marginal prices of Supplier 2 lagged by one period

Now both curves have similar trends and are almost identical in some periods. It seems that S5 chooses his prices completely independently from his costs or opportunity costs (in the sense of lost spot-market profits), since it is doubtful that S5's costs equal the one-period-lagged costs of S2. Especially if we consider S5's behavior in the circled area: S5 chooses a marginal price which is only slightly below the marginal price realized by $\mathrm{S} 2$ in $\mathrm{t}-1$, but then clearly determines the marginal price himself. In the following month S5 decreases his marginal price just slightly below the marginal price which would have emerged if S5 would not have been the marginal supplier. ${ }^{26}$ At first sight it does not seem rational to do so since he is pivotal and his bids have been accepted.

\footnotetext{
${ }^{26}$ The marginal price then would have been set by S2 with $9847 € / M W$ and S5 choses $9832 € / M W$ for the next month.
} 
However, S5 might wish to avoid being the marginal supplier and had expected a further increase of S2's marginal prices.

With this strategy S5 can not be blamed for the abuse of his dominant position by setting excessively high prices and can legitimate his bidding behavior with the "guess the clearing price" principle of discriminatory auctions. ${ }^{27}$ As orienting on historical marginal prices is a typical approach in PABA and often the best guess (see Swider, 2007), this strategy can be legitimized very easily.

In addition to the graphic representation in Figures 6 and 7 we estimate the effect of S2's marginal price from the previous month on S5's current marginal price using the OLS-regression

$$
p_{S 5, t}^{m}=\alpha+\beta_{1} p_{S 2, t-1}^{m}+\beta_{2} p_{S 2, t}^{m}+\beta_{3} p_{S 5, t-1}^{m}+\varepsilon_{t},
$$

where $p_{i, t}^{m}$ denotes supplier $i$ 's marginal prices in $t$. The estimation result from Equation 2 supports our observation of S5's strategic bidding and is displayed in Table 4. Neither S5's own history nor the simultaneous value of S2's marginal price but only S2's one-period lag has a significant impact on S5's marginal price. A 10 percent increase of S2's marginal price results in average 6.5 percent increase of S5's marginal price in the following month.

\begin{tabular}{l|llll}
\hline Variable & Coefficient & Std. error & P-Value & \\
\hline \hline constant & 1986.899 & 768.83 & 0.018 & $* *$ \\
\hline$p_{S 2, t-1}^{m}$ & 0.65 & 0.156 & 0.001 & $* * *$ \\
\hline$p_{S 2, t}^{m}$ & -0.073 & 0.154 & 0.641 & \\
\hline$p_{S 5, t-1}^{m}$ & 0.091 & 0.163 & 0.561 & \\
\hline \hline$R^{2}=0.84$ & & & \\
Adjusted $R^{2}=0.81$ & & & \\
F-Statistic $=32.164$ & & & \\
Prob(F-Statistic)=0.000 & & & \\
Durbin-Watson stat=2.18 & & & \\
Method: Least Squares & & \\
White heteroskedasticity-consistent std. errors \& covariance \\
\hline ** significant at the 5\% level, ${ }^{* * *}$ significant at the 1\% level
\end{tabular}

Table 4: Estimation results

Even though bidding on the expectations of marginal prices is rational behavior in PABA, it is somehow surprising that S5 does not have a better estimate than the previous months' marginal prices. In PABA higher marginal prices caused by supply reduction do not directly lead to higher prices for all suppliers. However, the correlation between S5's supply and S2's accepted capacity is significantly negative. Due to the fact that S2 can sell more capacity if S5 decreases his supply, it is of particular interest to take a look at the individual bid functions.

\footnotetext{
${ }^{27}$ Indeed the Federal Network Agency confirmed that the underlying idea in the auctions for reserve power actually is the "guess the marginal price" principle.
} 


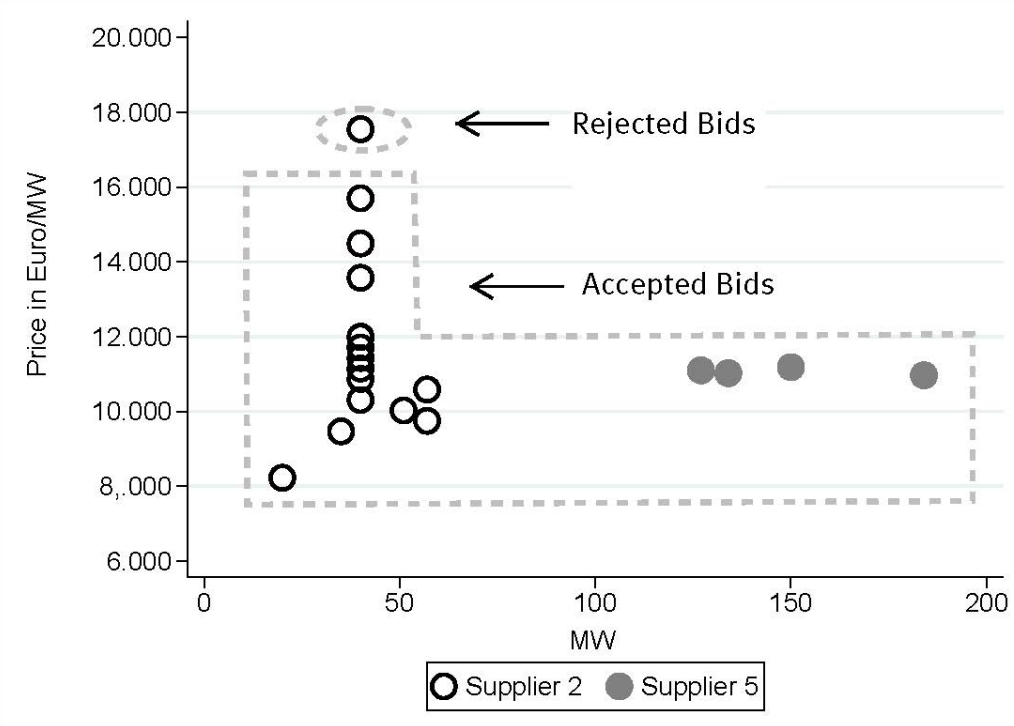

Figure 8: Bidding strategy of the two most dominant suppliers S2 and S5; exemplary: bids in July 2010

Considering Figure 8 shows why both suppliers achieve similar average prices even though S2 obtains significantly higher marginal prices in most auctions. The reason is the sizeable spread between S2's lowest and highest price. While S2 supplies a large number of bids with comparatively low quantity and a steep price function, S5 choses a flat supply curve with only a small number of large-volume bids. The described strategy has already emerged from Table 3 where S5 and S2 significantly differ in their average number of bids, average bid size and average standard deviations of the capacity prices per auction. However, Figure 8 additionally reveals that the majority of the supplied capacity of both suppliers is within the same price interval. As a consequence of S5's supply reduction, more expensive bids of S2 are awarded. Although S2 realizes higher marginal prices with his bidding strategy in scarcity situations, he does not earn higher prices per MW on average and thus initially supports the belief that withholding capacity is less attractive in discriminatory auctions. However, S2's marginal prices take on the role of a price booster and anticipate that a single awarded higher bid might be sufficient for triggering a long-term price increase. Due to the low capacity per bid, S2 does not suffer high losses if an expensive bid is rejected but increases his expected returns for the following periods since he can raise prices for the majority of his capacity and legitimate it with the guess the marginal price principle of PABA. This bidding strategy of S2 is sometimes referred as the hockey-stick-tactic in academic literature when it comes to discussions about UPA and can be a profitable strategy in scarcity situations. But its validity for discriminatory auctions is either neglected or negated (e.g. Rothkopf (2001), Harlbut et al. (2004), Cramton (2004)). However, our example clearly shows that in contrast to UPA this strategy obviously cannot work in a one-shot game but is profitable and hard to prosecute in repeated discriminatory auctions with highly pivotal suppliers. 
The impact of S5's supply on S2's marginal prices is estimated in the regression below and reveals a significant negative correlation between S5's supply and S2's marginal prices. In order to measure the relative effect we use logarithms. The estimation of

$$
\log \left(p_{S 2, t}^{m}\right)=\alpha+\beta_{1} \log \left(S U P P L Y_{S 5, t}\right)+\beta_{2} \log \left(p_{S 2, t-1}^{m}\right)+\varepsilon_{t}
$$

yields to the results displayed in Table 5 .

\begin{tabular}{l|llll}
\hline Variable & Coefficient & Std. Error & P-Value & \\
\hline \hline $\operatorname{constant}$ & 7.981 & 2.658 & 0.007 & $* * *$ \\
\hline $\log \left(S U P P L Y_{S 5, t}\right)$ & -0.609 & 0.256 & 0.027 & $* *$ \\
\hline $\log \left(p_{S 2, t-1)}^{m}\right.$ & 0.584 & 0.134 & 0.000 & $* * *$ \\
\hline \hline$R^{2}=0.746$ & & & \\
Adjusted $R^{2}=0.721$ & & & \\
F-Statistic=29.447 \\
Prob (F-Statistic)=0.000 \\
$\begin{array}{l}\text { Durbin-Watson stat=2.86 } \\
\text { Method: Least Squares, White heteroskedasticity consistent std. errors and cov. }\end{array}$ \\
**significant at 5\% level, ${ }^{* * *}$ significant at 1\% level
\end{tabular}

Table 5: Estimation results

Table 5 suggests that a 10 percent reduction of S5's supply leads to a 6 percent increase of S2's marginal prices on average. Bearing in mind that S5's supply has an impact on S2's marginal prices and thereby with one month delay on S5's marginal and average prices, S2 may obviously increase its prices by reducing its supplied capacity and stages itself as 'follower' while doing so. It can be noted that the drastic price increase was triggered by S5's supply reduction in combination with S2's bidding strategy. At the end of the observed period S5's supply returned to its initial level. However, prices remained at a higher level and all suppliers recorded significantly higher revenues. Even during the period of capacity reduction S5 did not suffer a drop in revenues but could even considerably increase them. Moreover, S5 might have achieved additional revenues by selling the withheld quantity at the spot market, provided that it was not unavailable because of technical restrictions. The development of S5's supply and revenues in the years 2009 and 2010 are illustrated in Figure 9. 

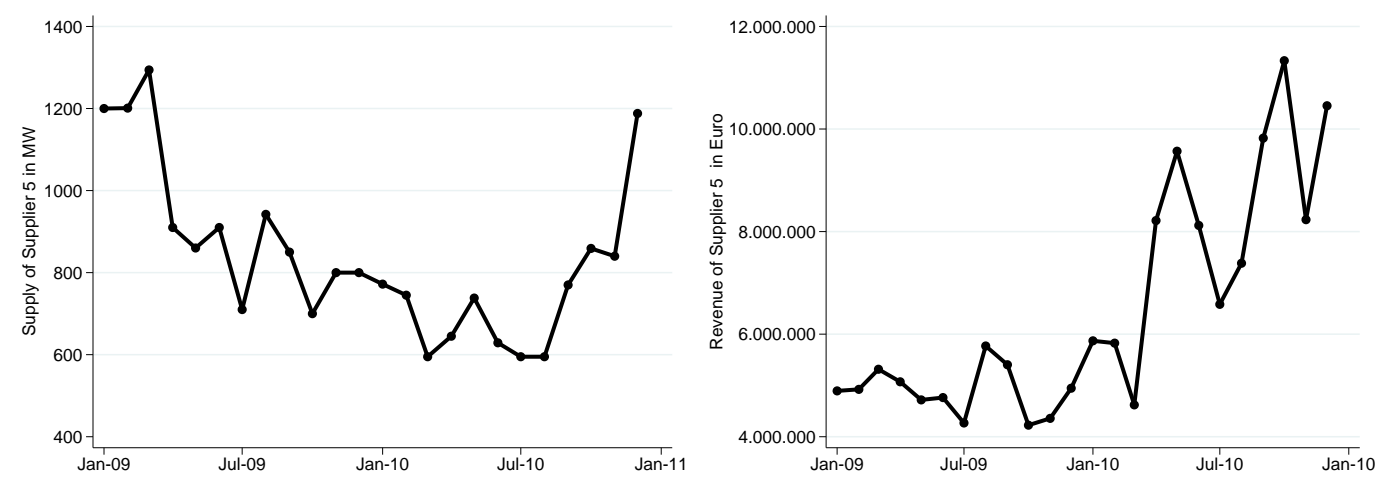

Figure 9: Development of Supplier 5's supply and revenue

Given the small number of observations due to the monthly auction iteration, technical possibilities and reliability of econometric analyses are fairly limited. Nevertheless, the analysis provides a first picture of gaming incentives in PABA when suppliers are pivotal, auctions are repeated regularly and demand is predictable but inelastic which should be the case in virtually all energy markets.

\section{Conclusion and Policy Implications}

Motivated by a drastic price increase we analyzed the German market for negative secondary reserve. As there were no conspicious movements on the EEX spot-market which serves as a onesided substitute market, the price increase did not appear to be supported by increased costs. We identified a concentrated market with highly pivotal suppliers in an environment with completely price-inelastic demand and high entry barriers. Against this background, we trace back the price increase to a reduction in supply of the most dominant supplier and the interaction of the two most powerful suppliers' bidding behavior afterwards.

Although the possibility cannot be ruled out that the reduction in the most dominant bidder's supply was not subject to systematic withholding but due to technical restrictions, market participants profited from it through repeated pretended "bad guessing". Thereby a spiraling price increase was initiated and prices maintained on a higher level even after supply was brought back to its initial volume again.

Thus, given regulatory threats, the deemed main advantage of pay-as-bid auctions (PABA) over uniform price auctions (UPA) and the popular belief that they reduce dominant suppliers' withholding incentives and diminish their ability to tacitly collude can be rebutted as general rule. In fact, while strategic capacity withholding immediately leads to higher average prices for all suppliers in UPA, in PABA bidders do not directly benefit from it but can generate extra-profits lagged by one period. This supports Kahn et al.'s (2001) proposition, that repetition of bidding proce- 
dures lend itself to collusion and changes of the auction design would not alter this. However, even if problems arising from market power are present under both frameworks, regulatory authority's power to deter its abuse is a crucial element for the efficiency of the market. Our findings suggest that the auction's settlement rule has a decisive role in explaining the price increase and reveals a particular argument against discriminatory auctions in electricity markets, which is broadly overlooked in the existing literature. As mitigation of the exercise of market power is one key task regulators have to deal with, power of deterrence instruments is inalienable to attain more efficient markets. This postulates that detection and legal prosecution of abusive behavior is feasible.

However, the present PAB settlement legitimizes cost independent price-setting thereby diminishing regulatory authorities' scope in comparison to UP as described below. Due to the inelastic demand, suppliers theoretically can charge infinitely high prices for the share of their capacity for which they are pivotal and bids would still get awarded. Assuming that a regulatory authority monitors the market, which is the case in virtually all energy markets, prices cannot diverge arbitrarily far from their costs under a UP framework. Since regulatory authorities should have at least a rough estimation of the cost levels, marginal suppliers would be confronted with the suspicion of market power abuse if their bids exceed a certain price limit according to GWB and TFEUS. In the US, FERC has the legal power to intervene when prices exceed an "unjust and unreasonable" level as observed 2001 in California. ${ }^{28}$ Hence, UPA have a fictional price limit which is directly linked to the marginal supplier's costs. If he exceeds it, he cannot justify his price-setting anymore and has to fear regulatory measures. The PABA does not have such a price limit since prices do not have to reflect costs but inherently legitimates and even forces inframarginal suppliers to charge prices above marginal or opportunity costs. In a competitive environment suppliers in PABA choose prices on the means of their expectations on the current marginal unit's costs and often the prices realized in the previous period is the best guess. Accordingly, price shocks do not (or at least slowly) decline even if costs decrease in future periods. This is in line with Swider (2007) who argues that a slow decrease in minute reserve prices after a shock in 2007 was due to slow adjustments of price forecasts in PABA. However, even in the case of dominant suppliers, which is typical for energy markets, suppliers can rely on the "guess the clearing price" principle of PABA and pretend to guess prices. Then, due to the low level of liquidity and the inelastic demand, a dominant supplier can reduce his capacity and still realize higher profits without having actively raised his prices beforehand in a PABA as well when auctions take place frequentely and demand uncertainity is low. Hence, with completely inelastic demand pivotal suppliers can divide the market tacitly between them and individually profit from that with lower fear of regulatory measures compared to a UPA. We conclude that proving abusive behavior becomes harder in

\footnotetext{
${ }^{28}$ see Wolak (2004).
} 
discriminatory auctions even when cost estimation is feasible since suppliers can hide behind the "guess the clearing price" principle and guessing prices wrong is not sufficient for legal prosecution. Considering that pivotal suppliers are rather the rule than the exception and there is only little demand elasticity in electricity markets in general (e.g. Borenstein et al., 2002), validity of our findings for other markets depends on the ex ante knowledge of the market's liquidity and the frequency of similar market situations. As both theoretic and experimental studies on auctions do not adequately take monitoring power as a deterrence instrument into account, there is space for further research on this topic.

\section{References}

[1] Ausubel, L., Cramton, P., 2002. Demand Reduction and Inefficiency in Multi-Unit Auctions. Working Paper, University of Maryland.

[2] Borenstein, S., Bushnell, J.B., Knittel, C., 1999. Market Power in Electricity Markets: Beyond Concentration Measures. The Energy Journal 20 (4), 65-88.

[3] Borenstein, S., Bushnell, J.B., Wolak, F., 2002. Measuring Market Inefficiencies in California's restructured Wholesale Electricity Market. American Economic Review $92(5), 1376-1405$.

[4] Bower, J., 2002. Why Did Electricity Prices Fall in England and Wales?. Working Paper EL 02, Oxford Institute for Energy Studies.

[5] Cabral, L., 2002. The California Energy Crisis. Japan and the World Economy 14, 335-339.

[6] Cramton, P., 2004. Competitive Bidding Behavior in Uniform-Price Auction Markets. Published in Proceedings of the Hawaii International Conference on System Sciences, January 2004.

[7] Cramton, P., Stoft, S., 2007. Why We Need to Stick with Uniform-Price Auctions in Electricity Markets. Electricity Journal 20 (1), 26-37.

[8] Dechenaux, E., Kovenock, D., 2007. Tacit collusion and capacity withholding in repeated uniform price auctions. The RAND Journal of Economics 38 (4), 1044-1069.

[9] ENTSO-E, 2012. Survey on ancillary services, procurement and balancing market design. ENTSO-E Working Group September 2012. Downloadable at https://www.entsoe.eu/fileadmin/user_upload/_library/resources/BAL/121022_Survey_on_AS_Proc 
[10] Evans, J., Green, R., 2003. Why did British Electricity Prices Fall after 1998?. Cambridge Working Papers in Economics 0326, Faculty of Economics, University of Cambridge.

[11] Fabra, N., 2003. Tacit Collusion in Repeated Auctions: Uniform versus Discriminatory. Journal of Industrial Economics 51 (3), 271-293.

[12] Fabra, N., Toro, J., 2003. The Fall in British Electricity Prices: Market Rules, Market Structure or Both? Industrial Organization 0309001, EconWPA.

[13] Fabra, N., 2007. Market Design, Market Power and Investment Incentives in Wholesale Electricity Markets. Workshop at Banca d'Italia 24 April2007. Download at http://www.eco.uc3m.es/ nfabra/Docencia/Seminarios/Roma.pdf

[14] Federico, G., Rahman, D., 2003. Bidding in an Electricity Pay-as-Bid Auction. Journal of Regulatory Economics 24 (2), 175-211.

[15] Growitsch, C., Mueller, G., Rammerstorfer, M., Weber, C, 2007. Determinantes of Pricing Development in the German Market for Tertiary Reserve Power. WIK Discussion Paper No. 300.

[16] Growitsch, C., Weber, C., 2008. On the electricity reserves market redesign in Germany. CNI-Working Paper No. 2008-1.

[17] Growitsch, C., Hoeffler, F., Wissner, M. 2010. Market Power on the German Balancing Power Market. Zeitschrift für Energiewirtschaft 34 (2), 139-148.

[18] Holmberg, P., 2009. Supply function equilibria of pay-as-bid auctions. Journal of Regulatory Economics 36, 154-177.

[19] Hurlbut, D., Rogat, K., Oren, S., 2004. Protecting the Market from "Hockey Stick" Pricing: How the Public Utility Commission of Texas is Dealing with Potential Price Gouging. The Electricity Journal 17 (3), 26-33.

[20] Hudson, R., 2000. Analysis of uniform and discriminatory price auctions in restructured electricity markets. Oak Ridge National Laboratory, Oak Ridge TN.

[21] Joskow, P., Kahn, A., 2002. A Quantitative Analysis of Pricing Behavior in California's Wholesale Electricity Market During Summer 2000. The Energy Journal 23 (4), $1-35$.

[22] Just, S., Weber, C., 2008. Pricing of Reserves: Valuing System Reserve Capacity against Spot Prices in Electricity Markets. Energy Economics 30 (6), 3198-3221. 
[23] Kahn, A., Cramton, P., Porter, R, Tabors, R. 2001. Uniform Pricing or Pay-as-Bid Pricing: A Dilemma for California and Beyond. The Electricity Journal 14 (6), 70-79.

[24] Klemperer, P., 2002. What Really Matters in Auction Design. Journal of Economic Perspectives 16 (1), 169-189.

[25] Mueller, G., Rammerstorfer, M., 2008. A theoretical Analysis of Procurement Auctions for Tertiary Control in Germany. Energy Policy 36 (7), 2620-2627.

[26] Muesgens, F., Ockenfels, A., Peek, M., 2011. Economics and Design of Balancing Power Markets in Germany. University of Technology Cottbus Working Paper $01 / 2011$.

[27] Newbery, D., 2003. The effect of NETA on wholesale electricity prices. Department of Applied Economics Cambridge, UK.

[28] Rassenti, S., Smith, V., Wilson, B., 2003. Discriminatory Price Auctions in Electricity Markets: Low Volatility at the Expense of High Price Levels. Journal of Regulatory Economics 23 (2), 109-23

[29] Richter, J., 2012. On the Interaction between Product Markets and Markets for Production Capacity: The Case of the Electricity Industry. EWI Working Paper No $11 / 09$.

[30] Rivero, E., 2011. European Balancing Markets. Energy Market (EEM), 2011 8th International Conference on the European, 333-338.

[31] Rothkopf, M., 2002. Control of Market Power in Electricity Auctions. The Electricity Journal 15 (8), 15-24.

[32] Schmalensee, R., Golub, B., 1984. Estimating effective concentration in deregulated wholesale electricity markets. The RAND Journal of Economics 15 (1), 12-26

[33] Sheffrin, A., 2001. Critical Actions Necessary for Effective Market Monitoring. Draft Comments Dept of Market Analysis, California ISO, FERC RTO Workshop.

[34] Sheffrin, A., 2002a. Predicting Market Power Using the Residual Supply Index. Presented to FERC Market Monitoring Workshop December 3-4, 2002.

[35] Sheffrin, A., 2002b. Empirical evidence of strategic bidding in California ISO real-time market", in Electric Pricing In Transition, Norwell, MA: Kluwer 267-281.

[36] Swider, D.J., 2007. Competition in the German Market for Power Systems Reserve?. Energiewirtschaftliche Tagesfragen 57 (9), 32-37. 
[37] Swider, D.J., Weber, C., 2007. Bidding under price uncertainty in multi-unit pay-asbid procurement auctions for power systems reserve. European Journal of Operational Research 181, 1297-1308.

[38] Twomey, P., Green, R, Neuhoff, K., Newberry, D., 2004. A Review of the Monitoring of Market Power. Cambridge Working Papers in Economics CWPE 0504

[39] Vandezande, L., 2011. Design and Integration of Balancing Markets in Europe. Dissertation, Katholieke Universiteit Leuven - Faculteit Ingenieurswetenschappen

[40] Wolak, F., Patrick, R., 2001. The Impact of Market Rules and Market Structure on the Price Determination Process in the England and Wales Electricity Market. National Bureau of Economic Research, NBER Working Paper Series No. 8248.

[41] Wolak, F., 2004. Lessons from International Experience with Electricity Market Monitoring. Center for the Study of Energy Markets (CSEM) Working Paper Series 134.

[42] Wolfram, C., 1998. Strategic Bidding in a Multiunit Auction: An Empirical Analysis of Bids to Supply Electricity in England and Wales. The RAND Journal of Economics 29 (4), 703-725. 